\title{
José de Barros: a vida, a arte, o estilo, a transgressão
}

\author{
Joana D'Arc de Sousa Lima \\ UFPE - Universidade Federal de Pernambuco
}

\section{Resumo}

Neste artigo procuro apresentar a trajetória do artista José de Barros nascido na cidade de Recife em Pernambuco nordeste do Brasil em 1943 e falecido, na mesma cidade, em 1994 do século vinte. Sua incursão no campo das artes se deu, sobretudo, em meados dos anos 1970 à década de 1990 marcando sua inserção no meio artístico via participação em exposições, sendo assunto da escrita critica de arte na imprensa, se vinculando a algumas instituições formativas em arte e via relações de amizade e trabalho com artistas já consagrados. Nesse artigo defendo a idéia que o contexto cultural, político e social dos anos 1970, o grupo de amigos com o qual compartilha ideias, práticas e modos de fazer, sentimentos e visões de mundo o conduziu a posturas - no campo das artes e da vida - próximas do que ficou rotulado por desbunde e experimentalismo. De outra parte, enfatizo sua importância, como professor de artes plásticas no âmbito da formação "do artista e ou docência em arte".

Palavras Chaves: História da Arte Brasileira; Ensino da Arte; José de Barros; Trajetória; Experimentalismo; Desbumde; Pernambuco.

\section{Abstract}

The purpose of this article is to present he life trajectory of the artist José de Barros born in the city of Recife, Pernambuco, in 1943 and died in 1994 in the same city. His immersion into the arts happened especially from the 70's until the 90's participating in expositions, receiving critics on the press, joining some art formation institutions and via his friend and collaborations with consecrated artists. I defend the idea that the cultural, political and social context of the 70's, his group of friends with whom he shared his ideas, led him to specific postures - in his personal and professional life - correspondingtowhatwasnameddesbundeandexperimentalism. Ontheotherhand, I emphasize his importance as an art teacher in the formation of the artist or the art teachers.

Keywords: BrazilianArtHistory; TeachingofArts; Jose de Barros; Life Trajectory; Experimentalism; Desbunde; Pernambuco. 


\section{Um olhar entre a arte de José de Barros Dias e o contexto político dos anos 1970}

Por isso é que eu sou um vampiro e com meu cavalo negro eu apronto. E vou sugando o sangue dos meninos e das meninas que eu encontro. Por isso é bom não se aproximar muito perto dos meus olhos, senão eu te dou uma mordida que deixa na sua carne aquela ferida (Jorge Mautner).

A arte de José de Barros é um ato heroico, um investimento e a afirmação de uma dada erótica, de uma dimensão desejante, de um corpo que pulsa e com larga gestualidade se fixa como marca, rastro, risco e código nas superfícies de suas pinturas, desenhos e gravuras. Uma afirmação do humano e da natureza - ausência total, por parte do artista, da separação radical entre esses dois enunciados: humano/natureza. José de Barros os junta na maneira como leva a vida e na forma como constrói e produz seus trabalhos. $\mathrm{O}$ artista afirma sua existência dentro de um estilo de vida alternativo, contra cultural. Produz uma estética para viver diferente, existir de outra maneira nos contextos do Brasil dos anos 1970, 1980, 1990, década em que nos deixou ${ }^{1}$.

O uso do seu corpo na produção artística foi prova disso. Um corpo não capturado pela disciplinarização dos corpos provocada pela ditadura militar, nem tampouco pela certo enrijecimento da postura herdada por parte de uma esquerda militante que, por necessidade, incorpora as tensões políticas na sua arquitetura corporal. José de Barros dançava na corda bamba. O artista opta pela existência de um corpo sensível: que sente o frescor da brisa, que dança ao som de Jorge Mautner, que segue os fluxos, os movimentos e busca a liberdade.

José de Barros compartilha de ideias e ideais, do gosto e das expectativas de uma geração dos anos 1970 que propôs a experimentação do corpo, das drogas, do desejo, da sexualidade, do cotidiano como existência e estética da vida - uma maneira de poder estar no Brasil da tortura, da captura do estado de exceção. A experimentação de criação total e exploração dos limites e das normas que regravam a sociedade naqueles anos. Zé de Barros - como era chamado por seus alunos, amigos e contemporâneos - afirma a estética do desbunde: experimentação e liberdade. Esses são possivelmente alguns dos legados que o artista deixou como estatuto para a arte e o fazer artístico. Sua linguagem é a exteriorização do seu ser, portanto o conjunto de sua produção apresenta no centro da linguagem, ou seja, no centro da obra, uma diferença e é essa que marca a transgressão de sua arte. A linguagem como lugar de expressão do sujeito, como campo de experiência.

José de Barros rompia com a caretice e as verdades absolutas. Sua atitude no trabalho era de certa irreverência e força intuitiva. Para a geração de jovens que viviam na $\infty<\infty<\infty<\infty<\infty<\infty \times \infty \times \infty \times \infty \times \infty \times \infty \times \infty \times$

1 O artista nascido na cidade do Recife em Pernambuco no nordeste do Brasil em 1943 falece vítima de complicações pelo vírus da AIDS em 1994 na mesma cidade. 
cidade do Recife e desejam ser artistas, na década de 1980, José de Barros foi uma referência importante como o "artista-professor", que se arrojava em experiências inusitadas com materiais diversos, nada usuais na época, sobretudo naquele espaço acadêmico regido por regras. Nos espaços de formação em que José de Barros era o professor, para além de uma sólida formação e aprendizado de técnicas da pintura, do desenho e da gravura em metal, que ele era exemplar, seus alunos eram convocados para pensar sobre qual o lugar da arte nisso tudo. E muitos descobriram que a arte tem um lugar central nessa história. A arte é o lugar, por excelência, em que se exerce a força de criação.

A mistura de linguagens, suportes e fazeres que o ateliê de José de Barros oferecia criava um ambiente de muitas trocas e muita liberdade criativa. Ouvir música experimental e MPB, pintar, fazer gravura, falar de arte e concretizar proposições plásticas, extrapolando as superfícies e os limites preestabelecidos, fazia parte da vivência que ele propunha a seus alunos no curso de educação artística da Universidade Federal de Pernambuco e amigos - um laboratório de experimentações que, muitas vezes, se estendia ao ateliê pessoal do artista. Os laços afetivos se intensificavam, e as trocas transbordavam as margens do lugar, das linguagens, dos saberes e da própria arte.

Para entender parte dessa experiência formativa no campo das artes plásticas que acontecia entre a instituição formal - curso de licenciatura em educação artística da UFPE - e a informal, que extrapolava o território da universidade e transbordava para o seu ateliê em Casa Forte, bairro localizado na região norte da cidade do Recife, me parece importante revisitar a trajetória do artista e recuperar práticas "pedagógicas" e modos e maneiras de ensinar no âmbito das artes plásticas realizadas pelo artista. Algo como uma pedagogia "zedebarriana” nomeada assim sua prática pedagógica pelo artista Maurício Castro em entrevista à autora.

\section{Trajetória / Percurso}

Você precisa aprender inglês. Precisa aprender o que eu sei. E o que eu não sei mais. E o que eu não sei mais. Não sei comigo vai tudo azul. Contigo vai tudo em paz. Vivemos na melhor cidade. Da América do Sul, da América do Sul. Você precisa, você precisa, você precisa. Não sei, leia na minha camisa. Baby, baby, I love you. Baby, baby, I love you. (Gal Costa)

José de Barros de Andrade Dias nasceu na cidade do Recife, em 1943. Foi desenhista, pintor, gravador e professor de artes da Universidade Federal de Pernambuco no curso de educação artística - atualmente funciona o curso de Licenciatura em Artes Visuais/UFPE. Coordenou, no período em que atuou como docente dessa instituição de ensino, o Ateliê de Gravura em Metal e um Ateliê de Pintura. Revelou-se interessado 
na área de artes plásticas, sobretudo na pintura, aproximadamente no ano de 1965 aos 22 anos de idade. Filho de Maria Eugênia de Andrade Dias, natural de Vitória de Santo Antão, dona de casa e de João de Deus de Oliveira Dias, natural de Água Preta, ambos municípios do estado de Pernambuco. João de Deus era engenheiro agrônomo, foi professor durante muitos anos na Universidade Rural de Pernambuco, onde chegou a ser reitor. Segundo depoimento de uma das filhas, Franci Oliveira Dias, quando solicitada a dar um depoimento, comenta,

Eita! Eu tenho mais orgulho ainda de falar de papai que de Zé de Barros, pois também foi um homem brilhante. Ele e mamãe nos deram uma educação primorosa e com poucos recursos. Não é fácil criar dez filhos com salário de professor. Dos dez filhos Zé foi o quarto e desde criança todos notaram sua criatividade para as artes, ele cresceu inteiramente se dedicando ao desenho, pintura, bico de pena, aquarela e muito interesse por litografia e gravuras em metal. Tanto foi sua determinação que nossos pais mesmo com dificuldades conseguiram pagar seus estudos em Paris, onde se especializou. Valeu a pena, papai tinha muito orgulho dele e qualquer visita lá em casa, ele e mamãe esqueciam da gente... rsrss... e só mostravam os trabalhos de Zé. Mas nós ficávamos contentes e orgulhosos também com o talento dele. Ele que era tímido e se retraia um pouco... rsrs... (Franci Oliveira Dias, relato à autora).

Com base no depoimento da irmã é possível considerar que os pais de José de Barros apoiaram sua formação, inclusive financeiramente. Ademais, não colocaram obstáculos morais para que ele prosseguisse nesse percurso e escolha profissional, segundo o depoimento acima, também pelo cuidado que o pai tinha com o pequeno legado artístico de José de Barros exibido nas paredes de sua casa, papai tinha muito orgulho dele e qualquer visita lá em casa, ele e mamãe esqueciam da gente, (Oliveira, idem, 2016), além do que viria depois quando o próprio João de Deus Dias passara a se dedicar a guardar e organizar o acervo $^{2}$ do filho.

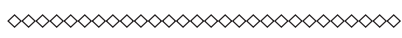

2 Seu acervo está sob guarda da família e merece ser exibido ao público pela importância que esse artista representa para toda uma geração e para a história das artes plásticas feita em Pernambuco; também pela qualidade e atualidade de sua obra, um acervo e um legado extremamente importante e experimental para a produção pernambucana das artes visuais. Em 2015 foi realizada uma exposição individual do artista intitulada 21 Anos Sem José de Barros, sediada na Galeria Janete Costa com curadoria minha e do professor Sebastião Pedrosa. Dentre muitos documentos que pesquisamos, tive acesso a um conjunto de cartas datadas em 1969, datilografadas e organizadas em uma pasta descrita por "Dossier de José de Barros, 2. Volume, ano 1969", não encontramos a pasta volume 1. Esse conjunto documental se refere ao período em que o artista, recém chegado, estava morando na França. As cartas revelam as angústias de estar fora do país, falta de emprego, a ansiedade com as aulas que estavam para iniciar, livros e discos que ele ouvia de artistas do Brasil. De certa maneira, um conjunto documental por meio do qual é possível construir relações que o 
João de Deus de Oliveira Dias era professor universitário com carreira na gestão administrativa da universidade, talvez essa trajetória profissional lhe possibilitasse ter um olhar diferenciado em relação ao potencial "criativo para as artes", que manifestava desde a infância de José de Barros. Esse capital cultural - herança dos grupos intelectuais, dentre eles professores, artistas, intelectuais de maneira geral - que a família valoriza e parece querer validar e manter apostando no dom e na formação do filho.

José de Barros estudou pintura na Escola de Belas-Artes da Universidade Federal de Pernambuco (1966-1967). Nos anos de 1965 a 1967, frequentou o Atelier de Pintura e Restauração da Galeria Retiro, na cidade do Recife. Entre 1968 a 1969, viajou para França, morou na cidade de Paris com o objetivo de cursar, segundo registro em carta remetida por seu pai datada 13 de janeiro de 1969 "aulas de História da Arte, na Faculdade de Letras da Universidade ${ }^{3 ”}$. Não obstante, encontramos em seu acervo pessoal um diploma que comprova que José de Barros estudou pintura no Departamento de Artes Plásticas do Centre Universitaire Experimental de Vincennes. ${ }^{4}$ Temos poucas referências sobre esse período que o artista passou fora do país. Também não sabemos os motivos de seu retorno, mas nas correspondências enviadas para a família José de Barros menciona "uma falta" da família e das relações familiares.

A saudade, fortemente presente e manifestada em suas cartas, somada à dificuldade em falta de trabalho. Nesse momento realizou pequenos "trabalhos" para manter-se na França, como mostra alguns dos registros fotográficos de seu álbum pessoal e verificável em cartas que enviava para a família. Em cartas comenta que pintava alguns tecidos, a seda, e vendia partes como lenço para alguns brasileiros e franceses, também procurou trabalho como "guia" em visita de grupos de brasileiros em Paris, mas não obteve sucesso nesse campo. A fotografia abaixo mostra um dos trabalhos que realizou na França, não sei exatamente se em Paris e ou na cidade de Vincennes fantasiado de índio.

Em 1970, de volta ao Recife, vai morar na cidade do Rio de Janeiro juntamente com o amigo de juventude Frederico da Luz Guerreiro. Nessa breve passagem pela cidade do Rio de Janeiro, ambos respiraram os novos ares e tiveram contato com os artistas

artista estabelece com a família, seu universo cultural, seus anseios e projetos de vida. Obviamente que esses relatos narrativos são também uma construção de si, dada em um momento específico e que conscientes ou não ficariam para a posteridade. Em especial as cartas foram modificadas na sua forma de escrita e no seu significado. Segundo relato da família essas cartas foram datilografadas e organizadas pelo pai do artista. Em uma das cartas datada de 06 de Janeiro de 1969 que Zé de Barros envia à família (não tem remetente), comenta, "O que não gostei foi das minhas cartas que papai mandou, porque não são autênticas... Sei, muito bem, que a intenção foi ótima, mas é que o meu estilo ou desestilo é outro. Depois a correção, apareceu até parágrafo começando por "Outrossim" e uma declaração minha em que encontro 'pletóricos'. Eu jamais diria uma palavra feia como essa... Outra coisa, no papel eu sou muito mais descontraído e se a coisa muda já não vou ter esse consolo. Em todo caso, gostaria que o meu pai querido e a minha mãezinha guardassem as minhas cartas originais, para quando eu voltar as poder reler."

3 Carta José Dias para José de Barros. Dossier de José de Barros, v. 2 (1969), 13/01/1969, datilografada, s/p. Acervo particular da Família Dias.

4 Carte D'etudiant, Centre Universitaire Expérimetal de Vincennes, 1969-1970. Documento do Acervo particular da Família Dias. 
jovens que frequentavam o Museu de Arte Moderna do Rio de Janeiro que, naqueles anos duros da ditadura militar, representava um espaço de encontros, sociabilidades e de produção das artes plásticas mais radicais.

Fred da Luz, amigo de infância e assíduo frequentador da casa dos pais de José de Barros, comenta em entrevista que ambos frequentavam muito a Praça de Burle Marx em Casa Forte, iam às festas "psicodélicas" que ocorriam na casa de Kátia Mesel e Lula Côrtes ${ }^{5}$, ambos jovens artistas que juntos formaram uma parceria cultural e afetiva. Em sua casa promoviam encontros desses jovens artistas da cidade ávidos por espaço de produção e trocas de ideias. Atitudes de irreverência, ousadias e muita adrenalina acionam o grupo ampliado que participava das festas e encontros propostos pelo coletivo Mesel e Côrtes em um contexto político que promovia o medo e o horror trazidos pelo regime militar nessa primeira metade dos anos 1970. As prisões arbitrárias, as perseguições a qualquer tipo de comportamento que gerasse suspeita de subversão, a tortura e os casos de colegas que desapareciam como num "passe de mágica", a repressão e a censura eram

$\infty<\infty<\infty<\infty<\infty<\infty<\infty<\infty<\infty<\infty<\infty<\infty$

5 Ambos muito jovens, Lula Côrtes e Kátia Mesel moravam juntos e sua casa era um ponto de encontro da intelectualidade jovem da cidade. Muitas festas ocorriam e misturavam-se linguagens, fazeres e ideias. Um espaço de sociabilidade rico e permeado por ideias libertárias, bem no espírito da geração da década de 1970. A trajetória dos dois artistas percorrem trilhas distintas, contudo se entrelaçam na maneira ousada e experimental de pensar a cultura e a arte brasileira, cada um sua singularidade e linguagem própria. Lula Côrtes nasceu em Recife em 1949, foi cantor, compositor, pintor e poeta brasileiro, em 2011 falece na mesma cidade. Foi um dos primeiros artistas a fundir ritmos regionais nordestinos com o rock and roll, juntamente com Zé Ramalho e outros artistas. O álbum Paêbirú em dupla com Zé Ramalho. Quase todas as cópias do álbum foram destruídas em uma inundação, tornando-o muito difícil de ser encontrado. O álbum foi relançado em 2005 pela gravadora alemã Shadoks Music, e em 2008 na Inglaterra pelo selo Mr. Bongo (MRBCD050). Em 1976 fez parte da banda de Alceu Valença. Após isso, gravou alguns álbuns solo pela gravadora Rozenblit que nunca foram lançados. Entre eles está Rosa de Sangue, que em 2009 foi finalmente lançado pela gravadora estadunidense Time-Lag Records (Time-Lag 041). Em 1980 finalmente teve um álbum solo lançado, chamado O Gosto Novo da Vida, pela gravadora Ariola. Durante a década de 1980, a maioria de seus trabalhos foram produzidos com a banda Má Companhia. Côrtes também não deixou de fazer algumas colaborações com Zé Ramalho em outros álbuns, incluindo o álbum de estreia do cantor de 1978, Zé Ramalho, o De Gosto de Água e de Amigos de 1985 e o Cidades e Lendas de 1996. Também publicou livros de poesia. Katia Mesel nasceu no Recife em 1948. Estudou Arquitetura e Artes Gráficas na UFPE. Começou a filmar em 8mm ainda estudando arquitetura, em seguida adquiriu uma câmera Super 8 e até 1986 realizou 20 filmes, a maior parte documentários. Em 1980 abriu a produtora ARRECIFE PRODUÇÕES. De 1984 em diante dedicou-se ao cinema, realizando inúmeros filmes e vídeos De 1991 à 1993 produziu e dirigiu o Programa o "Pernambucanos da Gema "semanal, com 30 minutos, na TV Pernambuco, tendo um saldo de 200 vídeos realizados sobre a cultura Pernambucana. Em 1995 foi convidada para representante de Cinema, Vídeo, Fotografia na Comissão Deliberativa do Sistema de Incentivo à Cultura de Pernambuco. Em 1996 e em 2005 foi eleita Presidente da Associação Brasileira de Documentaristas e Associação Pernambucana de Cineastas. 2002 - Foi convidada para representante de Audiovisual no Conselho de Cultura do Recife, ficando até 2007. 2006 - Entra para a diretoria da Associação de Produtores Cinematográficos do Norte e Nordeste - APCNN. Atualmente Kátia Mesel está envolvida com um projeto mais ousado. O seu primeiro longa metragem, "O Rochedo e a Estrela", está em fase de finalização. Conf. Informações em http://katiamesel.blogspot.com.br/, visitado em 04/06/2016. Sobre Lula Côrtes ver: TELES, José. Do Frevo ao mangue beat. São Paulo: Editora 34, 2000; TATIT, Luiz. Antecedentes dos Independentes. In: Arte em Revista. Independentes, Ano 6, nº, São Paulo, CEAC, 1984, p.30-34; COSTA, I. C. "Quatro Notas sobre a Produção Independente de Música”. In: Arte em Revista. Independentes, Ano 6, nº8, São Paulo, CEAC, 1984, p.06-21. 
exemplos de ações do estado brasileiro que produziam o medo, confinamentos e autoexílio da vida política e cultural. Não obstante, tal situação produziu simultaneamente atitudes de irreverência, comportamentos estéticos dissonantes que se materializavam em ações efêmeras, performances artísticas e produções culturais consideradas pelo crítico de arte Frederico Morais como arte guerrilha ${ }^{6}$.

Uma geração de artistas que, segundo Wally Salomão ${ }^{7}$, [essa geração] mesmo vivendo com todos os limites impostos pelo regime militar, na década de 1970, não se via apenas como uma vítima da ditadura. A censura e o controle, por exemplo, o fez [e parte dessa geração] abrir buracos respiradouros, aberturas para sua produção e deu propulsão a ela. No caso de Wally, surgiu à obra literária, uma coleção de 1972, que levou o nome de $\mathrm{Na}$ Corda Bamba, (...) que era o Brasil daquele momento que tinha uma coragem de se jogar no mundo que era movido pela compressão da ditadura (Wally Salomão, relato para o documentário, Anos 70, 2001).

Em dupla com Laison (cartunista, produtor cultural e escritor), Lula Côrtes lançou no início de 1973 o álbum Satwa, o primeiro disco independente da música brasileira moderna, com a participação de músicos que depois ficariam consagrados, como Robertinho de Recife. O álbum chegou a ser relançado na década de 2000 nos Estados Unidos pela gravadora Time-Lag Records. Em 1975, lança o raro e cultuado álbum Paêbirú em dupla com Zé Ramalho.

Humberto Magno, amigo que esteve presente com José de Barros nos anos 1970 até seu falecimento, comenta, em entrevista, era uma época pesada que a gente passou também... da repressão militar, mas também a gente era muito doído... (Humberto Magno, relato à autora), esse breve fragmento aponta para pensarmos na relação entre repressão militar e as possíveis atitudes fora do estabelecido, que na visão atual de Humberto Magno, com o olhar retrospectivo, "a gente era muito doido" revela comportamentos não usuais, desafios às regras morais e sociais impostas pelo sistema.

Em sua trajetória José de Barros - que não se engaja diretamente com a luta política - de volta a sua cidade natal, assumiu o cargo de coordenador do Atelier de Gravura em Metal da Escolinha de Arte do Recife (1971-1978), experiência marcante no processo de formação de jovens aspirantes a artista na época. Dessa experiência, o artista Gil Vicente se recorda da presença de Zé de Barros na sede da Escolinha, de sua impressionante presença como formador, diz Vicente, Durante meu período de seis anos, na

$\infty<\infty<\infty<\infty<\infty<\infty<\infty<\infty<\infty<\infty<\infty<$

6 Conf. Esses dados nas artes plásticas em Lima, Joana D’Arc de Sousa Lima. Trajetória artística e política de uma neovanguarda das artes plásticas no Brasil: 1968-1971. Recife: UFPE, 2011. Dissertação de Mestrado. Unesp/Araraquara, 2000.

7 Refiro-me, sobremaneira, ao depoimento dado pelo escritor no documentário, Anos 1970 da série panorama Histórico Brasileiro, produzido pelo Itaú Cultura, São Paulo: 2001. Coletânea. Filmes da série Panorama Histórico Brasileiro que aborda a produção cultural do Brasil do século XVIII à pós-modernidade nos seus aspectos históricos, políticos e econômicos. Sobre anos 60 - dir. Jean-Claude Bernardet, 2000, 30 min; Anos 70: Trajetórias - dir. Marcelo Gomes, 2001, 28 min e O Brasil da virada - dir. DainaraToffoli e Ninho Moraes, 2007, $31 \mathrm{~min}$. 
Escolinha... Primeiro me impressionou muito sua presença, depois fiz amizade com ele, por meio de Teresa (Carmem) e vi muitas vezes ele trabalhando (Gil Vicente, relato à autora).

Também coordenou o Ateliê de Pintura do Setor de Artes Plásticas da UFPB (1971). No ano de 1972, participou do Atelier de Gravura em Metal da Escolinha de Arte do Brasil no Rio de Janeiro. Nessa mesma cidade, lecionou gravura em metal no Núcleo de Atividades Criativas (NAC).

Outra passagem importante dentro de sua trajetória como artista foi sua participação na Oficina Guaianases de Gravura (1978), onde, entre outras experimentações tem-se a produção da série Impressões Amazônicas, após pesquisa realizada no estado do Amazonas, (1978). No final dos anos 1980, José de Barros com um grupo de artistas integra o coletivo Ateliê Coletivo (de Olinda). Segundo relato de José Claúdio,

(...) tudo começou com Samico e Baccaro, depois veio Luciano Pinheiro, Eduardo Araújo, Guita Charifker, aí chegou José Cláudio. Não sei se José de Barros veio desde o início. Mas tanto faz porque foi tudo na mesma época. Parece que antes se reuniam na casa de Guita; lembro - me de Gil Vicente lá e outros, Maurício Arraes, José Barbosa (relato à autora).

O coletivo se reunia em Olinda, em uma das casas de propriedade de Guiusepe Baccaro na Rua de São Bento. Apropriar-se do nome "Ateliê Coletivo" certamente traz, à luz daqueles dias, as memórias do primeiro Ateliê Coletivo da Sociedade de Arte Moderna do Recife (1952-1957). Segundo o livro Memória do Atelier Coletivo, entre seus integrantes, destacam-se: Abelardo da Hora, Anchises Azevedo, Armando Lacerda, Antônio Heráclito Carneiro Campello Neto, Bernardo Dimenstein, Celina Lima Verde, Corbiniano Lins, Genilson Soares, Gilvan Samico, Guita Charifker, Ionaldo Cavalcanti, Ivan Carneiro, José Cláudio, José Teixeira, Ladjane Bandeira, Maria de Jesus Costa, Nelbe Rios, Reynaldo Fonseca, Wellington Virgolino e Wilton de Souza. É possível levantar a hipótese que poderia haver nessa apropriação uma homenagem ao primeiro coletivo; também é possível reconhecer alguns artistas que atuaram nas duas organizações, e, por último, arriscar que poderia haver similitudes entre os ideais, práticas e maneiras de se fazer arte e seu entendimento em ambas as organizações.

Também José de Barros participou, juntamente com esse grupo, de "saídas" para pintar a paisagem dos arredores nesses anos. Atividade que provocava uma sociabilidade entre os artistas de sua geração e o olhar curioso dos novos e dos espectadores. Uma atividade que lembra muito as atividades dos artistas franceses do início do século XX em visita à paisagem tanto urbana quanto bucólica na tentativa de apreensão do real, tornando-o representação da pintura ou também como atitude de repúdio ao processo de industrialização e urbanização acelerada daqueles anos na França, marcando as atividades de grupos de artistas que buscavam o reencantamento do mundo e o retorno ao 
ambiente rural e primitivo.

Desde a década de 1960, participa de exposições individuais e coletivas em salões de arte, galerias e instituições particulares e públicas. Destaca-se Galeria de Arte do Teatro Popular do Nordeste, Recife (1966); XXV Salão Anual de Pintura do Museu do Estado de Pernambuco, Recife (1966) e no mesmo ano a I Bienal Nacional de Artes Plásticas, Salvador; A Gravura e o Desenho, Abelardo Rodrigues Galeria de Arte, Recife (1977); Guaianases I, Abelardo Rodrigues Galeria de Arte, Recife (1978); Guaianases II, Museu Guido Viaro, Curitiba, (1979) e no mesmo ano: Guaianases III: Gravura Brasileira, Rio de Janeiro e II Salão Nacional de Artes Plásticas, Rio de Janeiro; Coletiva de Janeiro - MAC/Olinda (1980); Impressões Amazônicas de José de Barros, Futuro 25 Artes Plásticas Ltda e Exposições de Desenhos, Centro de Artes e Comunicação (1980). Entre outras.

\section{A pedagogia Zedebarriana}

Na cartografia das artes visuais dos anos 1980 muitos espaços de formação, produção e exibição das artes visuais foram marcantes para formar e inserir uma nova geração de artistas (a chamada Geração 80 do Recife) no campo das artes visuais. Lugares, espaços, eventos e grupos aquecem o debate e o circuito artístico da década, por exemplo: Oficina Guaianases (1974, 1979-1995), Núcleo de Iputinga (1980), Exposição Internacional de Arte em Outdoor/Art-door (1981/82), Movimento de Arte Tátil (1982), Movimento de Arte e Cultura do Nordeste (1983), Grupo Aloísio Magalhães de Arte e Ofícios (s/d), Grupo Astrobelo (1982), Ateliê do Poço da Panela (Cavani), Ateliê Aurora (Luciano Pinheiro e Cavani, 1987), Ateliê e curso de extensão de José de Barros (1980), Carasparanambuco (1986), Formiga Sabe que Roça Come (1989), Ateliê Coletivo de Olinda (1989), Quarta Zona de Arte (1987/1990), Curso de educação artística e arquitetura na Universidade Federal de Pernambuco entre outros agenciamentos propositivos e ativos.

A geração mais jovem circulava em alguns centros de formação oficializados e não oficializados pelo poder público. Alguns desses lugares se destacam pela sua força formativa e aparece nas narrativas das memórias dos mais artistas jovens, exemplos, a Oficina Guaianases de Gravura, o Ateliê do artista José de Barros e o curso de extensão oferecido por ele na UFPE.

A UFPE oferecia o curso de Licenciatura Curta em Educação Artística, formando professores polivalentes para o ensino de artes nas escolas (teatro, música, dança e plásticas), ainda com uma estrutura curricular muito conservadora e com um corpo docente formado majoritariamente por professores oriundos da Escola de Belas Artes, criada em 1932. José de Barros era fruto dessa formação. E conviveu intensamente com artistas de sua geração como Luciano Pinheiro, Guita Charifker, Maria Carmem, Humberto Mag- 
no, Jairo Arcoverde, Bete Gattys, Rodolfo Mesquita, Montez Magno, Mauricio Arraes e Gil Vicente, ambos mais jovens, entre outros.

Formavam um grupo de amigos que compartilhavam amizade, afinidades nos fazeres e linguagens artísticas: todos eram pintores, experimentavam a gravura, tinham o desenho como maneira de expressão e prática recorrente na manufatura que antecedia o trabalho final. Compartilhavam ideias e ideais da juventude: encaminhavam-se para a profissionalização no campo artístico, por meio da manutenção de vínculos institucionais em organizações formais do campo - José de Barros vincula-se a Universidade como docente em artes; também pela organização de grupos de trabalhos coletivos, como aponta Luciano Pinheiro em entrevista, Numa época que as pessoas também gostavam de se juntar para trabalhar. Era uma coisa muito comum na nossa época, o agrupamento de artistas, (Pinheiro, relato à autora), a exemplo da Oficina Guaianases de Gravura,

Em 1978 foi fundado a procura dos artistas, dada a procura dos artistas que ouviam falar que havia um grupo de artistas fazendo gravura. (...) Mais ou menos nos anos 1980, paralelamente ao que aconteceu na Guainases, a esse movimento de gravura, alguns artistas começaram também a se unir em ateliers, a gente tinha essa prática. Assim, eu, dois, três artistas íamos nos reunir no atelier de Guita (Charifker) trabalhar, que ficava na Saldanha Marinho. Depois, às vezes vinham no meu atelier trabalhar. José de Barros tinha um ateliê que ficava em casa Forte, hoje é uma igreja enorme... No final dos 1980, mais ou menos... a gente falou, 'Porque a gente não funda um ateliê, em homenagem ao ateliê coletivo de Abelardo da Hora?

O artista morreu no Recife, em 1994, ano em que foi homenageado, por meio de uma exposição de litografias, Impressões Amazônicas, na Galeria Vicente do Rego Monteiro, Fundação Joaquim Nabuco.

O professor José de Barros, que se destacava no corpo docente do Departamento de Educação Artística por sua irreverência estética e experimental, proporcionou um espaço de liberdade criativa que se opunha à tradição acadêmica ainda muito presente na época. Segundo conta o professor adjunto da mesma instituição, Sebastião Pedrosa, então recém-chegado à UFPE:

[...] na universidade, eu o sentia um tanto marginalizado. Havia um Queralt [também professor do programa], que vinha de uma pintura muito séria, de cavalete construído, medido, pensado, corrigido, e mais outros professores: Milton Santos, Aurora, Arlinda também, enfim, estava todo esse pessoal da Escola de Belas Artes. Portanto, Zé de Barros era aquele que era mais marginal. Ele rompia com as coisas. Sua atitude no trabalho era de uma certa irreverência; por 
exemplo, pintar a tela no chão, despejar a tinta, mexer, fazer quase um corpo ritualista - ele tinha esse tipo, que era muito intuitivo [...]. Então, eu sentia que as pessoas viam aquilo como uma marginalização: “Ele está inventando, é um experimentalista, e só". Eu sentia isso nas entrelinhas (Pedrosa, relato à autora, 2004).

Esse relato mostra as relações sociais dentro do curso de Licenciatura em Educação Artística da UFPE: aqueles que veem José de Barros como um marginal ("experimentalista, e só"). Mas e o artista? Nessa perspectiva, adjetivos como "inventor" e "experimentalista" passam a sugerir uma negatividade em relação ao trabalho e à postura do artista no âmbito da instituição. Ao mesmo tempo, Sebastião Pedrosa dá sua visão do artista ("Ele rompia com as coisas. Sua atitude no trabalho era de uma certa irreverência [...] era muito intuitivo"), rejeitando a pecha que incidia contra o colega. Além de acenar para uma prática educativa mais livre das regras impostas pelo fazer artístico tradicional. Segundo Pedrosa, mesmo sublinhando o rigor formal que Zé de Barros tinha e que prezava em sua prática como professor, realça que havia na sua maneira de ensinar artes aos alunos uma intuição que facilitava a relação entre o ensinar e o aprender. Pedrosa considera que não havia um método que Zé de Barros seguia, mas antes, sua intuição que possibilitava um fazer/aprender rico e libertador para a experimentação artística em muitas direções.

O relato de memória da restauradora Pérside Omena explora a relação de troca e amizade que José de Barros estabelecia com seus alunos. Comenta que conheceu o Barros na Escolinha de Arte do Recife por intermédio da artista Teresa Carmem que atuava com conservação de obras de arte e ministrava cursos sobre gravura e conservação. Dessa convivência com José de Barros na Escolinha do Recife, Pérside o reencontra na Universidade Federal de Pernambuco. Era seu primeiro ano como aluna do curso regular de educação artística e logo se tornou uma espécie de "assistente" de José de Barros ajudando-o em pequenas tarefas e sendo reconhecida pelos demais discentes do curso como interlocutora entre eles e o professor, salienta, pela amizade que eu tinha logo as pessoas quando queriam alguma coisa, falavam: 'Pérside cadê a chave do armário? Fala com Zé de Barros isso, fala aquilo... Então, era aquela amizade que eu tinha... a gente saía junto e logo ele começou a dirigir no carrinho dele... eu estava junto lá com ele... Dirigia mal que só (risos). (Pérside Omena, relato à autora, 2016).

$\mathrm{O}$ depoimento de Omena nos apresenta um dos vieses que retratam o tipo de relação que José de Barros construía em seu exercício como professor no curso de Licenciatura em Educação Artística. Dito de outra maneira, entre o professor e o aluno, Barros estendia uma ponte que os ligava pelos laços afetivos, por meio das atividades didáticas do cotidiano e pelos fazeres artísticos e proximidades entre esses. A amizade aparece como a potência de sua pedagogia, era por meio dela que as relações de ensino aprendizado se constituíam, o desejo se aflorava e a disponibilidade em permanecer no 
curso ou de ser e assumir-se como artista se consolidava.

Para a geração de jovens artistas, ou de alunos do curso de Licenciatura em Educação Artística da UFPE, José de Barros foi uma referência pedagógica importante. Citado nas entrevistas como o "artista-professor", que se arrojava em experiências inusitadas com materiais diversos, nada usuais na época, sobretudo num espaço acadêmico tradicional como era então aquele. Importante relato da arte/educadora Dora Arouxa, à época uma jovem iniciante no curso, ilumina o aspecto da amizade entre professor e aluno/a proposto por Barros e revela-se como o traço fundamental de sua pedagogia - o afeto e a liberdade de experimentação e o respeito pelo percurso e saberes individuais:

Conheci o artista e professor Zé de Barros, no meu primeiro período de faculdade quando cursava Licenciatura em Educação Artística na UFPE, no início dos anos 1980. Naquele momento eu estava vivendo o deslumbramento de estar no CAC estudando arte, quando entrei no Atelier Livre de Pintura, que era ministrado por ele. A empatia foi assim imediata, e se estabeleceu entre nós uma amizade, pois ele era uma pessoa muito acessível e era muito fácil gostar de Zé, como todos o chamavam. Naquela época eu queria fazer pintura, pois era para mim uma prioridade, e foi assim que Zé foi iluminando o caminho que eu percorria no início daqueles tempos. Como aluna eu queria saber tudo, tirar todas as dúvidas, e, ele em sua sabedoria ia desvendando os mistérios e segredos das tintas aos poucos. Uma característica dele era não desprezar aquilo que o aluno já trazia (ou seja, o desenho, o estilo) ele sempre respeitava a vontade do aluno, o que o aluno queria fazer. Ele acatava o desenho e a poética do aluno. Na sua didática, ele rompia com os paradigmas e dogmas acadêmicos (embora tivesse formação acadêmica) e passava para nós alunos as concepções modernistas. Mostrava sempre ao aluno as possibilidades técnicas, percursos e novas experiências. Zé acompanhava a produção de cada aluno, e dava o encaminhamento dele, dizia o que pensava sugeria mudanças, nós como alunos podíamos acatar ou não, ele dava liberdade de escolha não impunha nada. Mas não deixava de dar a opinião dele. O melhor era que, além disso, Zé nos incentivava à pesquisa e a experimentação, um avanço para a época, porque no curso na Universidade, havia uma ênfase nas pinturas acadêmicas com temas restritos a naturezas mortas e o desenho de modelo vivo, sem flexibilizar nada. No atelier com Zé, a pesquisa de materiais, as técnicas e mudanças de suportes foi fundamental para minha formação. Pintávamos nos mais variados suportes: plástico, papelão, tecidos e fazíamos papel artesanal. Nossas aulas também ultrapassavam as paredes do atelier do CAC, ele organizava passeios artísticos em outros espaços, e assim fomos para o Sítio da Trindade, Praça da Jaqueira, Olin- 
da, Museu do Estado. Onde fazíamos desenhos de observação das paisagens de cada espaço. Também incentivava os alunos a frequentarem exposições e mostras nas galerias da cidade. Lembrando que a cena artística em Recife nos anos 1980 era efervescente, se pintava e se produzia muito, e também havia muitos salões de arte, o do Museu do Estado, o Salão dos Novos, entre outros. Também falávamos de arte, discutíamos o que estava sendo produzido por outros artistas. Ao final de cada semestre sempre havia exposição dos trabalhos no próprio CAC ou em outros espaços, inclusive no Museu do Estado, também levamos a "Exposição do Padrão à Criação", para a Escola de Belas Artes na Bahia durante uma SBPC, eu, entre outros alunos e Zé que sempre participava de tudo. (Dora Aroucha, relato à autora, 2016, grifo nosso).

Esse olhar retrospectivo da arte educadora Aroucha é bastante elucidativo porque localiza com precisão algumas das estratégias pedagógicas que José de Barros propôs durante o período em que ela estava vinculada ao curso. Entre outros aspectos Dora realça em seu depoimento o respeito que Barros tinha em relação ao saberes, aptidões, desejos e opiniões que cada um dos alunos carregava em sua história de vida. Esse respeito possibilitava a minha opinião um fortalecimento da autonomia do aprendiz e a estruturação de seu percurso poético, pois, segundo o relato, o professor não deixava de dar sua opinião e os orientava em relação às técnicas e materiais, ele dava liberdade de escolha não impunha nada. Mas não deixava de dar a opinião dele.

Também comenta que em sua didática, José de Barros rompia com os paradigmas e dogmas acadêmicos (embora tivesse formação acadêmica) e passava para nós alunos as concepções modernistas (idem), esse breve fragmento alude certamente ao fato que Barros desprezava as maneiras de ensinar a arte por meio das regras e dos tratados que regiam o ensino da arte na Escola de Belas Artes. Embora tenha sido aluno da Escola, o artista primava pelo rigor formal - saber fazer - mas ensinava que a arte era um exercício de liberdade, de experimentação e de envolvimento entre a vida e a expressão poética do que se vive e sente. Nesse sentido, era visto por seus alunos como uma ilha "modernista" em meio a um mar de posturas e posições acadêmicas. $\mathrm{O}$ incentivo a pesquisa e aos experimentos era uma marca desse posicionamento novo, lido como modernista no âmbito da universidade que mantinha ênfase, segundo Aroucha nas pinturas acadêmicas com temas restritos a naturezas mortas e o desenho de modelo vivo, sem flexibilizar nada (ibidem).

Marcante ainda no relato supracitado é a incorporação em suas aulas de visitas a demais instituições e museus de arte fortalecendo, em minha opinião, o trabalho de formação do olhar e ampliação do universo cultural dos alunos. No depoimento de Aroucha fica explícito que a intenção do professor José de Barros com o programa de visitas era para a produção de desenhos de observação das paisagens de cada espaço. Esse últi- 
mo aspecto parece ser o que motivava o professor Zé de Barros a organizar essas saídas de campo. Como já comentado em outra parte desse artigo, em sua trajetória artística Barros participava com outros artistas de atividades de saídas ao campo para pintar e registrar a paisagem local. Um exercício que marcou a formação dos pintores, ou melhor, de parte dos pintores pernambucanos. Não obstante, comenta Aroucha, ocorria também conversas sobre arte, de maneira geral, e sobre o que se produzia por outros artistas, além do incentivo, por parte de Barros, para que seus alunos frequentassem exposições e mostras nas galerias da cidade, lembrando que a cena artística em Recife nos anos 1980 era efervescente, se pintava e se produzia muito, e também havia muitos salóes de arte, o do Museu do Estado, o Salão dos Novos, entre outros.

Ao término do período letivo - semestre -, Barros organizava uma mostra expositiva para que os trabalhos realizados nesse tempo fossem exibidos ao público no próprio Centro de Artes e Comunicação - CAC, ou em outros espaços como, supracitado por Dora Aroucha. No horizonte maior de sua abrangência esse tipo de proposição dentro do trabalho pedagógico do professor é extremamente importante, porque além de dar visibilidade ao processo educativo coordenado pelo docente, também revela a valorização e o cuidado que o docente tem em relação ao processo e percurso de aprendizagem do grupo em questão. Também a proposição de expor os trabalhos acaba por ser uma atividade laboratorial de aprendizagem no que diz respeito à formação do olhar curatorial (seleção e escolha do que vai ser mostrado e como vai ser mostrado), ao aprender a fazer uma exposição - montagem, difusão e divulgação da mostra. Todas as etapas da realização da exposição, vivenciada pelo grupo de alunos, termina por se transformar em um lócus de saber fazer praticado por esses e no horizonte maior vir a se transformar numa experiência de trabalho no sistema das artes. Dora Aroucha comenta que uma das exposições organizadas, a saber, "Exposição do Padrão à Criação", que grosso modo tratou-se de mostrar trabalhos que pictóricos que foram feitos sobrepostos a tecidos que já possuíam estampas gráficas padronizadas pela indústria de tecidos. Esse exercício artístico de apropriação do suporte e sobreposição de camadas pictóricas em grandes extensões foi levado para a Escola de Belas Artes na Bahia durante uma edição do Encontro da Sociedade Brasileira Progresso da Ciência, marcando a experiência de formação de Dora e dos demais alunos que participaram desse evento.

Dito isso, o que tratamos aqui deve ser visto como uma densa experiência formativa no campo da arte educação para a formação de artistas, artistas educadores, arte educadores, gestores culturais e de museus, conservadores e restauradores, designs entre outros fazeres e profissionais que estão hoje no meio artístico, nas escolas e universidades, em museus e instituições de cultura e que passaram pela Universidade e conviveram com o professor José de Barros. Do ponto de vista formal José de Barros foi um professor que zelava pela afetividade e amizade, sem isso a relação ensino aprendizagem não se efetivava. O respeito aos saberes que acompanhavam seus alunos, seus desejos e quereres e a liberdade de escolha de cada um deles, segundo os depoimentos aqui cedidos e trabalhados, era conservador. Como orientador do grupo, José de Barros é lembrado por seus 
alunos como uma referência de exímio conhecedor de pintura e gravura e extremamente rigoroso com as técnicas e maneiras de fazer, não se omitindo a orientar e comentar os trabalhos de seus alunos. Além das aulas presenciais realizadas no CAC, Barros propunha aulas de campo, visitas a demais exposições, diálogos sobre a produção contemporânea entre outras maneiras de ampliação do universo artístico e cultural dos alunos.

O diferencial também estava em que José de Barros oferecia um curso de extensão aberto a todos os interessados, inclusive os que não eram do meio acadêmico, o que possibilitou a muitos jovens artistas frequentarem suas aulas sem ser alunos da instituição. Entre eles, seguramente estiveram Alexandre Nóbrega, Aurélio Velho, Dantas Suassuna, Flávio Emanuel, Joelson Gomes, José Patrício, José Paulo, Marcelo Silveira, Maurício Castro, Maurício Silva, Oriana Duarte, Paulo Meira, Pérside Omena, Rinaldo Silva, Renato Vale e Gil Vicente - os dois últimos no início dos anos 1990 -, entre outros.

Indagado sobre esses encontros, o artista Joelson Gomes se recorda deles com carinho:

Eu, particularmente, desenvolvi uma amizade paralela com Zé de Barros; eu achava ele tão legal, era uma dessas pessoas que você dava boas risadas. Era tão legal aquilo ali (...). Na verdade, o que Zé de Barros apresentou, assim, foi um encontro de alguns artistas que estavam querendo se afirmar e encontraram um lugar onde eles podiam trabalhar e expor suas ideias. (...) Era um centro de malucos, mas malucos bacanas (relato à autora, 2004).

Essa mistura criava um ambiente de muitas trocas e de muita liberdade criativa. Ouvir música experimental e MPB, pintar, fazer gravura, falar de arte e extrapolar as superfícies e os limites preestabelecidos fazia parte da vivência; um laboratório de experimentações que muitas vezes era estendido para o ateliê do artista.

(...) ele criava situações, ele pegava estopas e fazia moldagens e, de repente, ele tinha aquela ousadia de pegar aquilo e sair para o público de aula e romper. Então, o espaço do CAC ficava cheio de coisas, umas figuras estranhas, aquilo era interessante; ele quebrava, vamos dizer, a coisa tão intimista... Isso contaminava os aprendizes. Era muito positivo para o curso na graduação e para o curso de extensão dele. Todos se referem com muita... saudade. (Pedrosa, depoimento à autora, 2004).

Muitos desses artistas organizaram grupos e espaços coletivos de produção e exibição das artes visuais. Mauricio Castro fundador do Quarta Zona de Arte (Recife, 1988), comenta a influencia de José de Barros quanto a adoção de uma pedagogia: 
Acho que nós empregávamos a pedagogia "zédebarriana”. Era muito parecida a forma de liberdade, a falta de rigor técnico era um exercício de liberdade. Nós gostávamos daquela liberdade que foi colocada por Zé de Barros e repetíamos como a fórmula do sucesso. E todo mundo gostava muito.

Por fim, falar da pedagogia zedebarriana é trazer novamente à luz dos dias atuais a fala fantástica do crítico Mário Pedrosa, a arte é um exercício experimental de liberda$d e$. Sem esse exercício de liberdade do qual nos fala o crítico, obviamente estava ele se referindo às práticas artísticas erigidas na década de 1960, não é possível a produção de atravessamentos - entregas e disponibilidade para o outro, para a diferença - e sem esses não há possibilidade de processos de aprendizagens. Aprendemos, primordialmente com o outro e com a diferença.

Acredito que só é possível ocorrer atravessamentos quando há respeito pelos saberes prévios, quando há trocas afetivas, amizades e um corpo de ideias compartilhadas e aceitas pelo coletivo. Para que haja atravessamentos é preciso que cada um dos que estão no grupo possa ter espaço de fala e de construção, é preciso que uns aprendam com os outros, é preciso que o mediador seja reconhecido como tal e dele possa emanar proposições que possibilitem os desejos fluírem, se expandirem e transbordarem. Os atravessamentos fazem parte das experiências construídas. A experiência tem que ser um acontecimento, fazer atiçar as narinas, arrepiar a pele e estremecer o corpo - provocar o deslocamento.

O que o artista José de Barros parece ter realizado foi essa experiência, um atravessamento nas vidas de jovens aprendizes que em suas memórias carregam lembranças do artista e do mestre como sendo chave de seus destinos.

Frequentei o atelier durante todo o meu período de faculdade, fui me afastando quando comecei a estagiar e assumir outros compromissos. Depois comecei a ensinar na Rede Pública no Estado e depois na Prefeitura do Recife. Mas, sempre passava lá no atelier para revê-lo. Hoje depois de todos esses anos, vejo como foi importante ter participado do atelier naquela época, e o quanto ele era a frente do seu tempo, e nos apontava a pós modernidade. Não posso negar a influência que Zé teve sobre no meu trabalho como professora, e na minha relação com meus alunos e no meu caminho como artista. Hoje considero que o verdadeiro mestre, é aquele que compartilha o conhecimento com seus discípulos e este conhecimento é capaz de transformar. E assim foi Zé. Meu Mestre. (Dora Aroucha, relato à autora, 2016). 


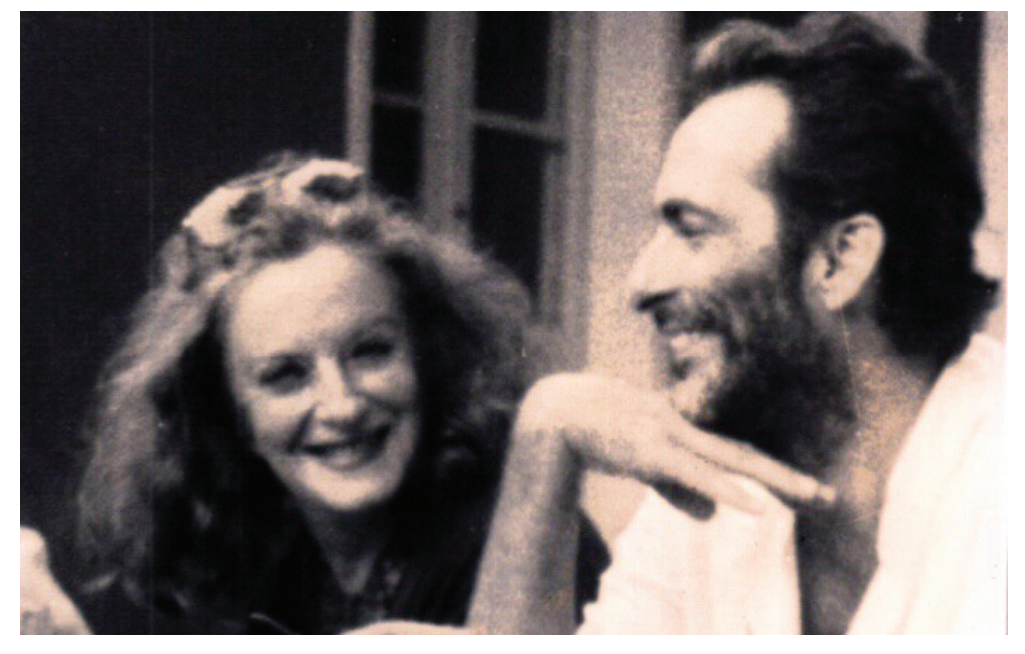

Fig. 1 - José de Barros e sua grande amiga Guita Charifker.

Autor desconhecido

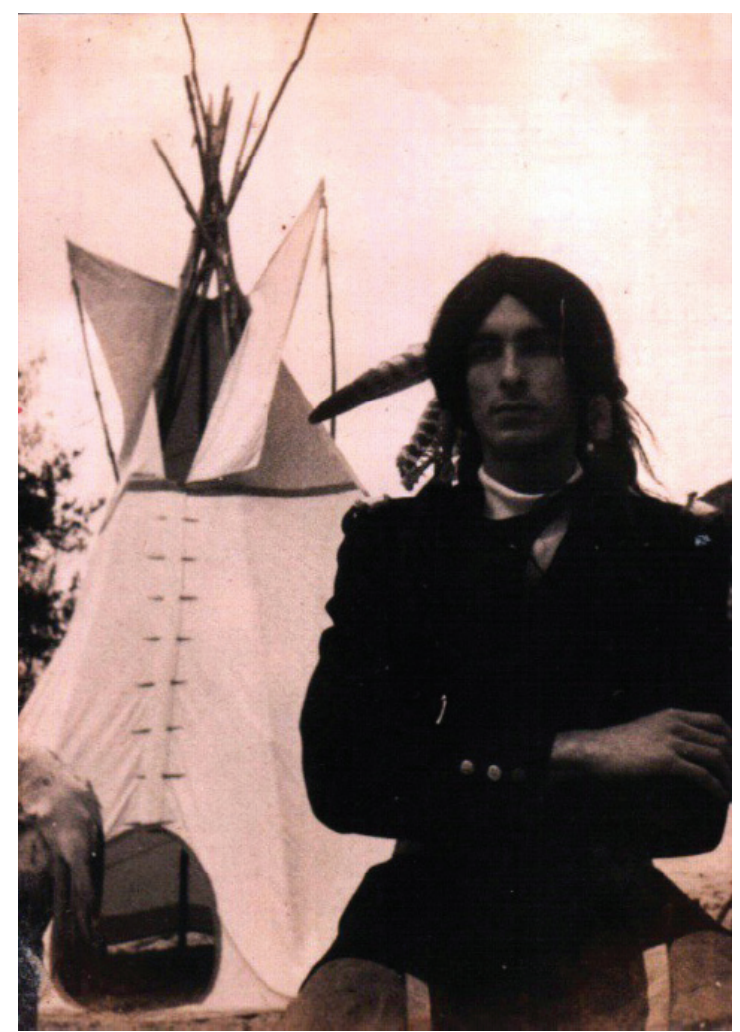

Fig. 2 - José de Barros fantasiado de índio brasileiro quando de sua passagem pela França (1969) para descolar uns trocados 


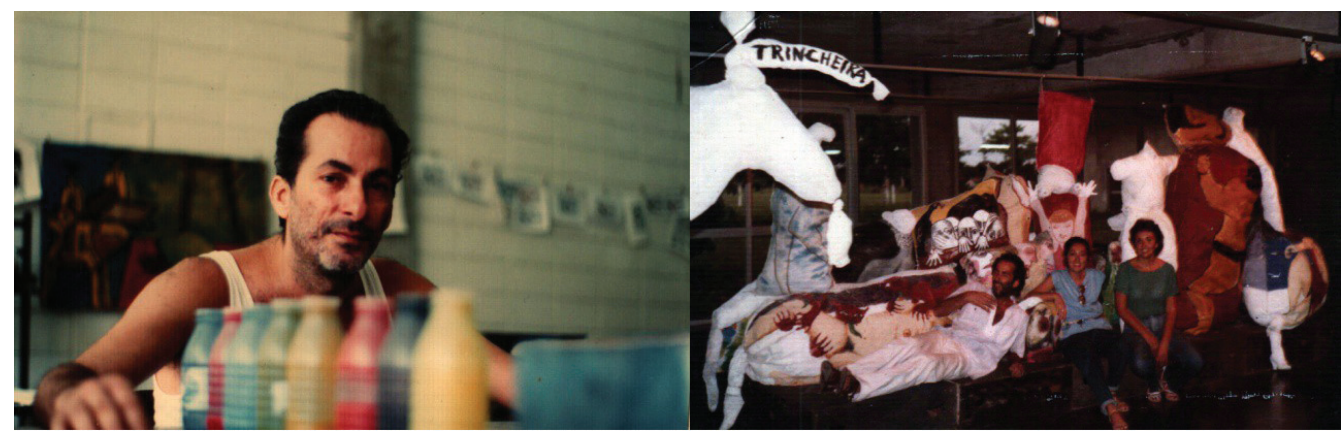

Fig. 3 - José de Barros no Centro de Artes e Comunicação
Fig. 4 - Imagem que conta parte de suas experiências como docente

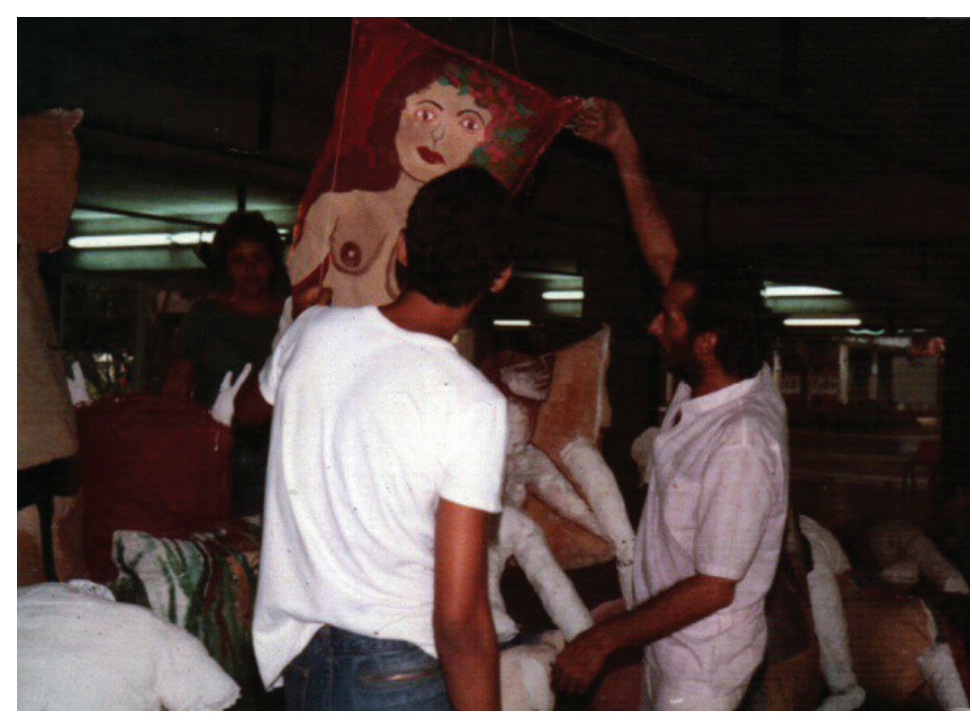

Fig. 5 - José de Barros preparando montagem de exposição no Centro de Artes e Comunicação

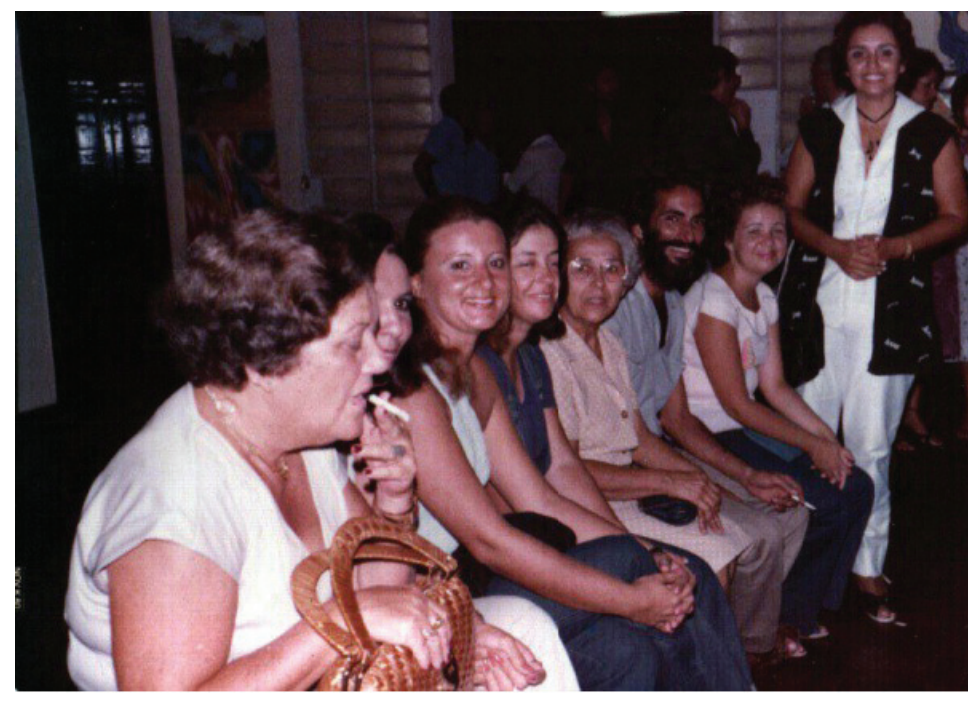

Fig. 6 - José de Barros acompanhado de alunas. Entre essas, da direita para a esquerda, Dora Uchoa 


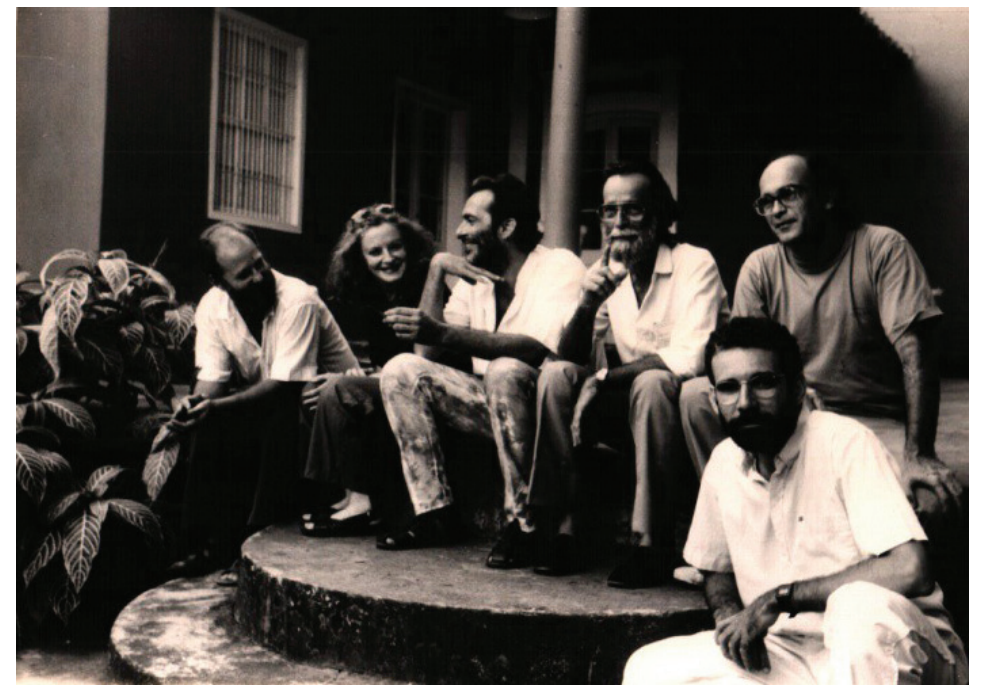

Fig. 7 - José de Barros com amigos artistas

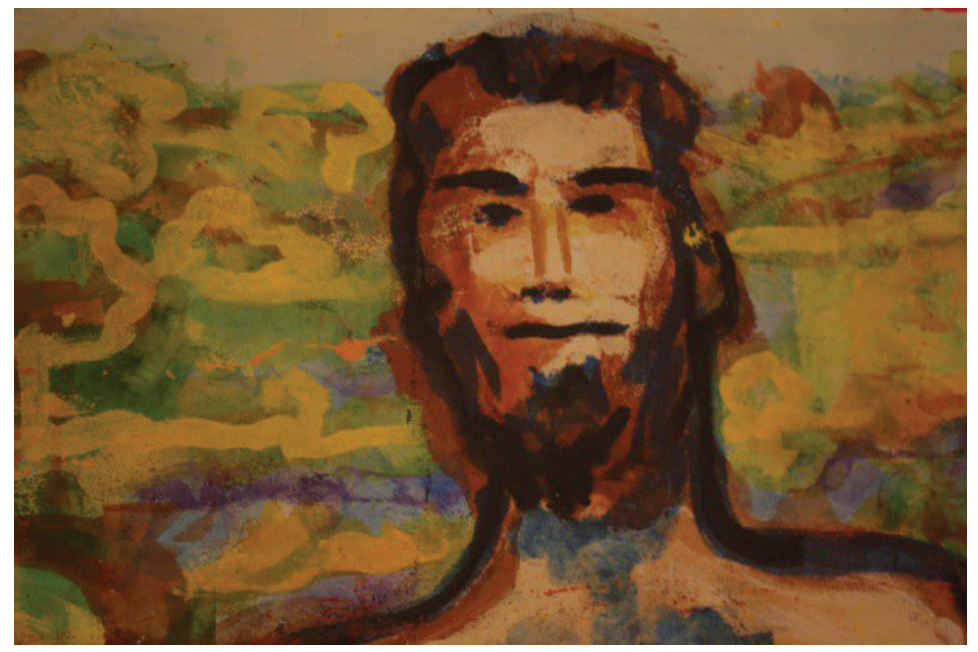

Fig. 8 - Fragmento de pintura de sua autoria, Menino do Rio

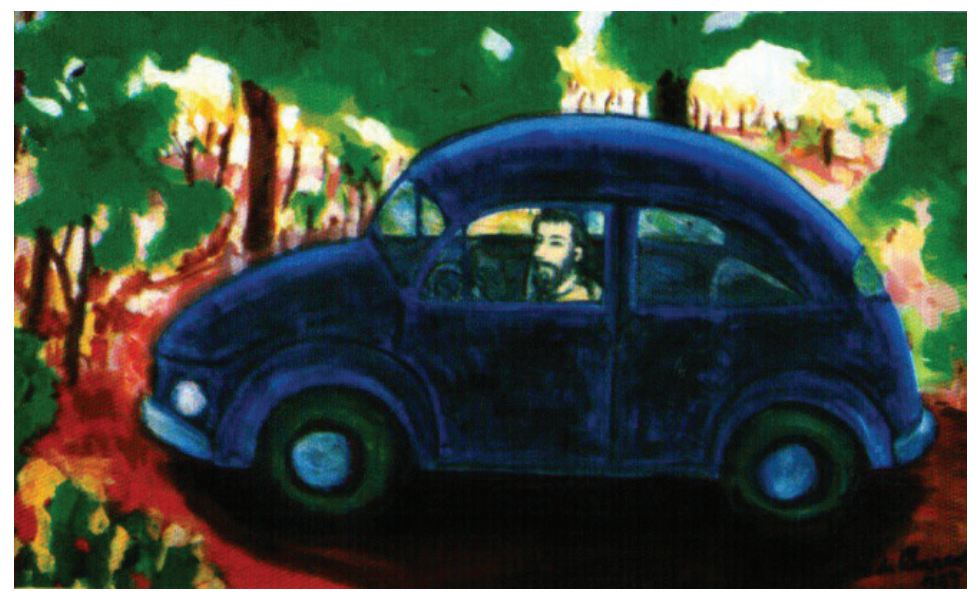

Fig.9 - Recorte de um cartaz de uma das suas muitas exposições. Destacamos um fragmento de seu fusquinha azul que habita nas memórias de seus amigos 


\section{Referencias bibliográficas}

AJZENBERG, Elza. Exercícios Estéticos de Liberdade. São Paulo, ECA-USP. Tese de livre- -docência, São Paulo, ECA-USP.

BARBOSA, Ana Mae. A imagem no ensino da Arte. $6^{\circ}$. ed. São Paulo, Perspectiva, 2005. $134 \mathrm{p}$.

2001.

John Dewey e o ensino da arte no Brasil. São Paulo: Cortez, [org]. Inquietações e mudanças no ensino da arte. São Paulo,

Cortez, 2002.

va, $1995.132 \mathrm{p}$.

[Org.]. Arte-Educação no Brasil. $3^{\circ}$. ed. São Paulo: Perspecti-

BOLLNOW, Otto F. Pedagogia e Filosofia da Existência: um ensaio sobre formas instáveis da educação. São Paulo: Editora Vozes, 1971. 242 p.

DE KETELE, Jean-Marie. Itinéraire et Itinérance. In HASSENFORDER, Jean. Chercheurs en Éducation. Paris: INRP/L'Harmatan, 1999, pp. 151-158.

DEWEY, John. Coleção Os Pensadores, John Dewey. São Paulo, Abril Cultural, 1980.

DIMITROV, Eduardo. Regional como opção, regional como prisão: trajetórias artísticas no modernismo pernambucano. São Paulo: USP, 2013. Tese apresentada ao Programa de Pós-Graduação em Antropologia Social da Faculdade de Filosofia, Letras e Ciências Humanas da Universidade de São Paulo para obtenção do título de Doutor em Antropologia.

LARROSA, Jorge. Experiência e paixão. In: LARROSA, Jorge. Linguagem e educação depois de Babel. Belo Horizonte, Autêntica, 2004.

LIMA, Joana D’Arc de Sousa. Trajetória artística e política de uma neovanguarda das artes plásticas no Brasil: 1968-1971. Recife: UFPE, 2011. Dissertação de Mestrado. Unesp/Araraquara, 2000.

Cartografias das Artes Plásticas no Recife nos anos 1980: Deslocamentos Poéticos e Experimentais. Recife: Ed. Universitária/UFPE, 2014.

MORIN, Edgar et.al. Educar para a era planetária: O pensamento complexo como método de aprendizagem no erro e incertezas humanas. Lisboa: Instituto Piaget, 2003. $124 \mathrm{p}$.

TATIT, Luiz. Antecedentes dos Independentes. In: Arte em Revista. Independentes, Ano 6, nº , São Paulo, CEAC, 1984, p.30-34; COSTA, I. C.“Quatro Notas sobre a Produção Independente de Música”. In: Arte em Revista. Independentes, Ano 6, nº, São Paulo, CEAC, 1984, p.06-21.

TELES, José. Do Frevo ao mangue beat. São Paulo: Editora 34, 2000. 


\section{Entrevistas realizadas}

Betty Gatis

Dora Aroucha

Franci Dias

Fred da Luz Guerreiro

Gil Vicente

Humberto Magno

Jairo Arco Verde

Joelson Gomes

José Paulo

Marcelo Silveira

Mauricio Arraes

Mauricio Castro

Mauricio Silva

Márcio Almeida

Luciano Pinheiro

Perside Omena

Sebastião Pedrosa 